\title{
The study of metribuzin migration in lysimeters
}

\author{
Victoria Kolupaeva ${ }^{1, *}$, Anna Kokoreva ${ }^{1,2}$, Tatyana Bondareva ${ }^{1}$ \\ ${ }^{1}$ Russian Scientific-Research Institute of Phytopathology, 5, st. Institute, ownership 143050, Bolshye \\ Vyazemy, Moscow region, Russia \\ ${ }^{2}$ Lomonosov Moscow State University, 1, Lenin mountains, 119991, Moscow, Russia
}

\begin{abstract}
Metribuzin is a mobile pesticide widely used in agriculture and has great potential for soil migration. In addition, weather and soil conditions in the non-chernozem zone of Russia contribute to the movement of pesticides in the soil. The behaviour of metribuzin was studied in a lysimetric experiment. The experiment was carried out at the lysimeters of the Soil Research Station of Moscow State University from June 2016 to December 2017. Mertribuzin was applied in lysimeters in maximum recommended and eightfold rates two years in a row. Used in the recommended rate, metribuzin was detected in the samples of lysimetric water once at a concentration of $14 \mu \mathrm{g} \mathrm{L}^{-1}(6 \%$ of the samples analyzed). Applied in the eightfold rate, it was detected in $39.5 \%$ of samples, the maximum concentration was $180 \mu \mathrm{g} \mathrm{L}^{-1}$. The experiment revealed that metribuzin is able to leach bottom of the soil profile. The concentration of metribuzin found in the variant with the recommended rate is lower than the hygienic index adopted in Russian Federation for metribuzin, which indicates that the risk of metribuzin application for people is low.
\end{abstract}

\section{Introduction}

All over the world, there is growing concern about the contamination of ground and surface water by pesticides. For example, in Denmark, pesticides are found in 5\% of surveyed wells [1].

Metribuzin is herbicide that is often found in groundwater around the world [2-8]. It is widely used in Russian Federation for weed control in potatoes, tomatoes, corn, soybeans, chickpea, and pea crops. The physical and chemical properties of a pesticide are responsible for the potential to leach are persistence and mobility. In this sense, metribuzin has high solubility and low sorption and persistence, which suggest high potential for movement in soil [9-17]. Metribuzin has been detected in 4\% of the analyzed cases [8]. Groundwater concentration of metribuzin have been reported up to $0.1 \mu \mathrm{g} \mathrm{L}^{-1}$ and above $[2,3,5,6]$.

Climatic conditions in most regions of the Russian Federation (low temperatures and large amounts of precipitation) contribute to the migration of pesticides in the soil profile and into groundwater. The pesticide monitoring program implemented by the Federal Service for Hydrometeorology and Environmental Monitoring (Roshydromet) does not include investigation of groundwater. Lysimetric studies represent an opportunity to

* Corresponding author: v.kolupaeva@vniif.ru 
receive, in conditions as close to natural as possible, an information on the concentrations of pesticides in the groundwater leachate, which, to some extent, can replace monitoring data.

The purpose of this work was to study the migration of the metribuzin in Albic Glossic Retisols loam soil in a two-year lysimetric experiment.

\section{Methods}

\subsection{Pesticide}

Metribuzin is a selective, systemic herbicide with contact and residual activity from the group of triazinones. It is used before and after sprouting. By persistence this herbicide refers to unstable active ingredients: $\mathrm{DT}_{50}$ varies within 5-13 days, in terms of migration ability - to mobile active substances: $\mathrm{K}_{\mathrm{foc}}=3-82 \mathrm{~mL} \mathrm{~g}^{-1}$ [18].

\subsection{The lysimeters of the soil research station of Lomonosov Moscow State University (MSU)}

The experiment was carried out on the lysimeters of the Soil Research Station of the MSU from June 2016 to December 2017. The lysimeter station was built in 1960 and modernized in 2015. Each of the lysimeters has an area of $8 \mathrm{~m}^{2}$ and a depth of $175 \mathrm{~cm}$. Two lysimeters were used for the study. The soil of the lysimeter is Albic Glossic Retisols [19] loam with the normal structure of the soil profile. The properties of soil are shown in Table 1 [20].

Table 1. Some physical and chemical properties of the soil.

\begin{tabular}{|c|c|c|c|c|c|}
\hline $\begin{array}{l}\text { Horizon } \\
\text { depth, cm }\end{array}$ & $\begin{array}{c}\text { Sand }(>50 \mu \mathrm{m}) / \text { Silt }(2-50 \\
\mu \mathrm{m}) / \text { Clay }(<2 \mu \mathrm{m}), \%\end{array}$ & $\underset{\mathrm{g} \mathrm{cm}}{\rho,-3}$ & $\begin{array}{l}\mathrm{C}, \\
\%\end{array}$ & $\mathrm{pH}_{\mathrm{H} 2 \mathrm{O}}$ & $\begin{array}{l}\mathbf{K}_{\text {filtration, }}, \\
\text { m day }^{-1}\end{array}$ \\
\hline $0-20$ & $5.3 / 89.7 / 5.0$ & 1.28 & 2.18 & 5.81 & 0.70 \\
\hline $20-35$ & $4.1 / 88.8 / 7.1$ & 1.45 & 0.77 & 5.73 & 0.54 \\
\hline $35-60$ & $5.9 / 89.8 / 4.3$ & 1.49 & 0.65 & 5.73 & 0.36 \\
\hline $60-120$ & $7.6 / 86.2 / 6.2$ & 1.50 & 0.60 & 4.50 & 0.18 \\
\hline $120-150$ & $18.4 / 75.5 / 6.1$ & 1.56 & 0.81 & 4.50 & 0.08 \\
\hline
\end{tabular}

\subsection{Lysimeter experiment}

Metribuzin was applied into the lysimeters using a knapsack sprayer twice - in June 2016 and June 2017. The application rates for the active substance were maximum recommended (lysimeter 6) and eightfold (lysimeter 5) rate $-0.98 \mathrm{~kg} \mathrm{ha}^{-1}$ and 7,8 $\mathrm{kg} \mathrm{ha}^{-1}$ respectively. Samples of lysimetric leachate were taken at least once a month, soil samples -2 times a year (in the spring before and after treatment and in the autumn). Soil samples were collected by a drill (making up a mixed sample of 5 individual) in increments of $5 \mathrm{~cm}$ to a depth of $40 \mathrm{~cm}$. In addition, the volume of water leachate was regularly recorded.

\subsection{Metribuzin analysis}

Quantitative determination of the content of metribuzin in the soil and in water was carried 
out in accordance with the Russian methodological guidelines. Limits of quantification in soil and water were $10 \mu \mathrm{g} \mathrm{kg}^{-1}$ and $1,0 \mu \mathrm{g} \mathrm{L}{ }^{-1}$ respectively.

\section{Results and discussion}

The mean annual air temperature in the years of the experiment was close to the mean longterm values (Table 2). The amount of precipitation in 2016 exceeded the mean annual value by $90 \mathrm{~mm}$, and in the summer - by $121 \mathrm{~mm}$. In 2017, the total annual precipitation was higher than the mean annual value by $223 \mathrm{~mm}$, and during the summer - by $104 \mathrm{~mm}$. During the whole experiment (1.5 years) a washing water regime was observed. The volume of monthly water percolation ranged from 20 to $120 \mathrm{~mm}$. Differences between lysimeters in the values of water volume were within $10 \%$.

Table 2. Mean annual and seasonal air temperature and precipitation (meteostation of Moscow State University).

\begin{tabular}{|c|c|c|c|c|c|c|}
\hline \multirow{2}{*}{ Period } & \multicolumn{3}{|c|}{ Mean air temperature, ${ }^{\mathbf{0}} \mathbf{C}$} & \multicolumn{3}{c|}{ Mean precipitation, $\mathbf{~ m m}$} \\
\cline { 2 - 7 } & $\mathbf{1 9 9 7 - 2 0 1 4}$ & $\mathbf{2 0 1 6}$ & $\mathbf{2 0 1 7}$ & $\mathbf{1 9 9 7 - 2 0 1 4}$ & $\mathbf{2 0 1 6}$ & $\mathbf{2 0 1 7}$ \\
\hline Whole year & 5.8 & 6.5 & 6.5 & 732 & 822 & 955 \\
\hline Spring & 6.0 & 7.8 & 6.7 & 136 & 146 & 220 \\
\hline Summer & 18.3 & 19.5 & 17.6 & 228 & 349 & 335 \\
\hline Autumn & 5.6 & 4.4 & 6.2 & 197 & 200 & 179 \\
\hline Winter & -6.9 & -5.7 & -4.3 & 170 & 125 & 219 \\
\hline
\end{tabular}

Metribuzin was found in the soil once in autumn of 2016 in upper 5-cm layer in lysimeter with eightfold application rate. Its content in the layer was less than $10 \%$ of the applied amount. This was facilitated by the high degradation rate of metribuzin in the soil.

38 water leachate samples from lysimeter with eightfold application rate and 16 samples from lysimeter with recommended rate were analyzed. Used in accordance with the regulation, metribuzin in leachate was detected once ( $6 \%$ of the all samples) 1 month after the first application in 2016, the concentration was $14 \mu \mathrm{g} \mathrm{L}^{-1}$ (figure 1). Applied in eightfold rate, metribuzin was found in $39.5 \%$ of water samples: $15.7 \%$ of the samples analyzed had a concentration of metribuzin from 0 to $10 \mu \mathrm{g} \mathrm{L}^{-1}, 23.8 \%$ - above $10 \mu \mathrm{g} \mathrm{L}^{-1}$. Maximum herbicide concentration was $180 \mu \mathrm{g} \mathrm{L}^{-1}$, the average $-25.0 \mu \mathrm{g} \mathrm{L}^{-1}$ (table 3 ). It can be assumed that in the lysimeter with the recommended rate, metribuzin was detected much less due to limitations of analytical method.

For comparison, it should be noted that in an experiment conducted in Denmark to monitor the content of metribuzin in soil water at a depth of 1 and 2 meters, as well as in groundwater at a depth of $4 \mathrm{~m}$, no herbicide was detected [21]. In a lysimetric experiment in Canada, metribuzin was detected at a depth of $85 \mathrm{~cm}$ at concentrations up to $4 \mu \mathrm{g} \mathrm{L}^{-1}$ for 2 months after treatment. [22]. In a field experiment in the United States, metribuzin was found in groundwater at a depth of $2.6 \mathrm{~m}$ at concentrations of up to $10 \mu \mathrm{g} \mathrm{L}^{-1}$ in $13 \%$ of samples [23]. 


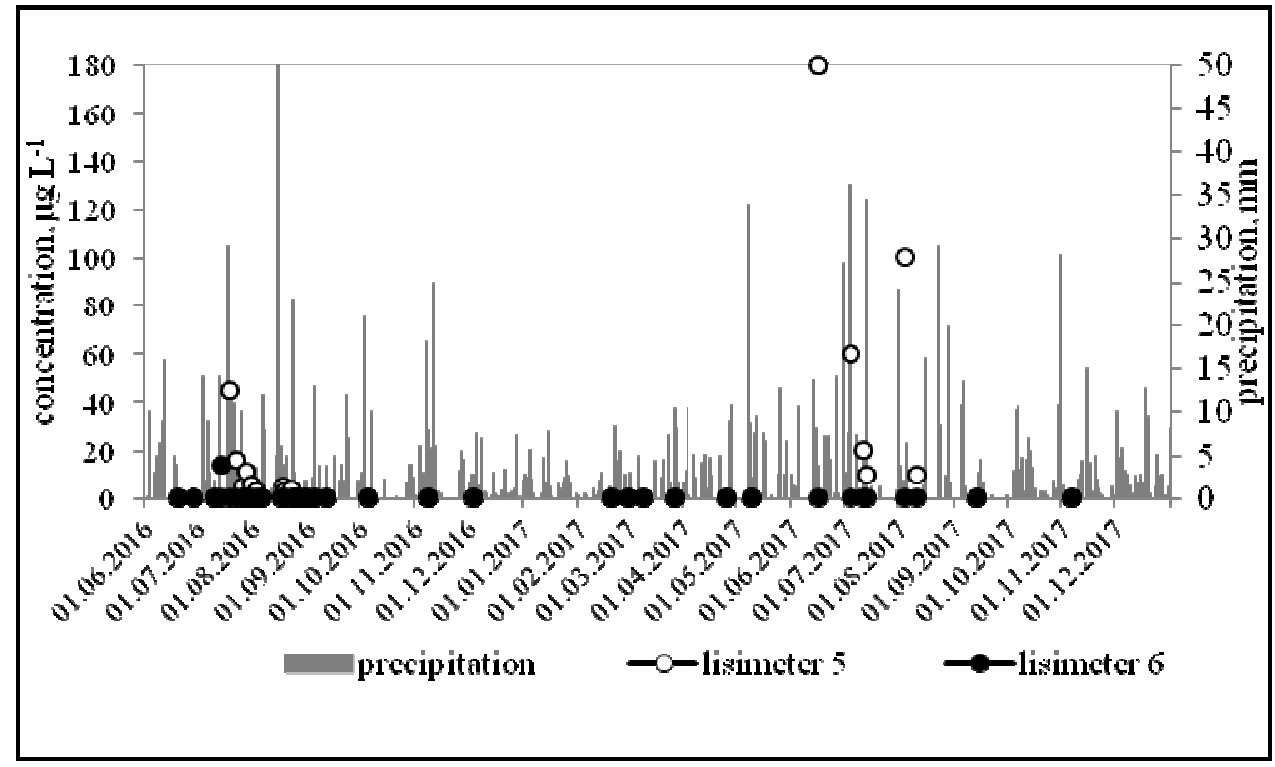

Fig. 1. Precipitation and metribuzin concentration in leachate.

It should also be noted that the pesticide applied in an eightfold rate was detected in water samples in 2016 and 2017 for 2 months after treatment. Apparently, this is due to the rapid decomposition of the herbicide.

Thus, migration of herbicide through the soil into lysimetric water can be explained by high mobility of metribuzin molecule as well as properties of Albic Glossic Retisols loam soil and climatic condition during experiment. The low content of organic matter in the soil and high rainfall contributed to the penetration of metribuzin bottom of the soil profile. In addition, during the summer of 2016, several showers characterized of high intensity fell. It also cannot be excluded movement of the herbicide on the preferential migration routes, since it is known that in soils of heavy texture with macropores and cracks, there is a fast transport of water, a non-chromatographic flow is formed, in contrast to the flow of the chromatographic type (uniform and stationary front of movement). This assumption is supported by the fact that metribuzin immediately appeared in the leachate in high concentrations, which indicates the breakdown of the substance through macropores.

Table 3. Metribuzin concentration in leachate.

\begin{tabular}{|c|c|c|c|}
\hline \multirow{2}{*}{ Pesticide } & \multicolumn{3}{|c|}{ Concentration in leachate, $\boldsymbol{\mu g} \mathbf{L}^{-\mathbf{1}}$} \\
\cline { 2 - 4 } & Maximum & Mean & $\mathbf{8 0 \%}$ percentile \\
\hline Lysimeter 5 & 180.0 & 25.0 & 10.8 \\
\hline Lysimeter 6 & 14.0 & 0.6 & 0.0 \\
\hline
\end{tabular}

In the Russian Federation, when registering pesticides, concentrations are compared with hygienic standards in drinking water - human indexes, which is equal for metribuzin to $100 \mu \mathrm{g} \mathrm{L}^{-1}$. According to this index, the risk of metribuzin used in accordance with the regulations for people is low. The value of Russian hygienic index significantly exceeds the threshold value adopted in the EU (for metribuzin it is 1000 times higher). Thus, a risk assessment based only on accounting for human harm cannot protect the groundwater itself as a natural object and aquatic organisms from the adverse effects. Risk of metribuzin applied in recommended rate for fish and daphnia is low; risk for macrophytes - high $\left(\mathrm{EC}_{50}\right.$ for macrophyts is $8 \mu \mathrm{g} \mathrm{L}^{-1}$ ). 


\section{Conclusion}

The experiment showed that metribuzin is able to migrate bottom of the soil profile. This is facilitated by weather conditions (high rainfall) and soil (low organic matter content, the presence of macropores) properties.

Lysimetric studies are an effective and informative tool for studying the migration of pesticides, allowing to detect the concentrations of applied substances directly in the flow outside the soil profile and can serve for the risk assessment of migration of pesticides into groundwater for registration purposes. In fact, the concentration measured at the bottom of lysimeters could represent an "index of risk" for groundwater.

The risk of metribuzin for people assessed in accordance with the indexes adopted in Russia is low.

\section{Acknowledgments}

This study was supported by State Project of Russian Scientific-Research Institute of Phytopathology, by the Russian Scientific Foundation, project no. 16-16-04014 and by RFBR according to the research projects no. 18-34-00801.

\section{References}

1. L.F. Jorgensen, J. Kjar, P. Olsen, A.E. Rosenbom, Chemosphere 88, 554 (2012)

2. Pesticide Management Planning Committee Response (2017) https://www.mda.state.mn.us/sites/default/files/inlinefiles/CombinedRecommendation LettersAug2017.pdf

3. M. Stenrød, M. Almvik, O. M. Eklo, A. L. Gimsing, R. Holten, K. Künnis-Beres, M. Larsbo, L. Putelis, K. Siimes, I. Turka, J. Uusi-Kämppä, Environ. Sci. Pollut. Res. 23, 15779 (2016)

4. W. Brüsch, A.E. Rosenbom, N. Badawi, L. Gudmundsson, F. von Platten-Hallermund, C.H. Hansen, C.B. Nielsen, F. Plauborg, P. Olsen, The Danish Pesticide Leaching Assessment Programme (2016)

5. Summary Report of Pesticide Sampling Groundwater Monitoring Program (Delaware Department of Agriculture, 2018) https://agriculture.delaware.gov/wpcontent/uploads/sites/108/2018/04/Groundwater-Monitoring-Program-Summary.pdf

6. A.E. Rosenbom, J. Kjær, T. Henriksen, M. Ullum, P. Olsen, Environ. Sci. Technol. 43(9), 3221 (2009)

7. P. Zhang, P. Aagaard, F. Nadim, L. Gottschalk, K. Haarstad, Integr. Environ. Assess. Manag. 5, 414 (2009)

8. P.L. Toccalino, R.J. Gilliom, B.D. Lindsey, M.G. Rupert, Groundwater 52, 112 (2014)

9. V. Pot, P. Benoit, M. LeMenn, O. M. Eklo, T. Sveistrup, J. Kværner, Pest. Manag. Sci., 67, 397 (2011)

10. M.R. Rigi1, M. Farahbakhsh1, K. Rezaei, J. Agr. Sci. Tech. 17, 777 (2017)

11. A. López-Piñeiro, D. Peña, A. Albarrán, D. Becerra, J. Sánchez-Llerena, J. Env. Manag. 122, 76 (2013)

12. D.J. Sarkara, A. Singha, N. Singha, B.S. Parmara, A. Kumar, Pestic. Res. J. 24(2), 138 (2012)

13. A.C.D. Guimarães, K.F. Mendes, T.F. Campion, P.J. Christoffoleti, V.L. Tornisielo, 
Planta Daninha 37, 019181505 (2019)

14. B.N. Rodrigues, F.S. Almeida, Guia de Herbicidas, 7th ed. (Londrina, PR, Brazil, 2018)

15. N. Singh, Raunaq, S.B. Singh, J. Environ. Sci. Health, Part B 47, 89 (2012)

16. K.F. Mendes, R.N. de Sousa, V. Takeshita, F.G. Alonso, A.P.J. Rego, V.L. Tornisielo, Geoderma 343, 40 (2019)

17. A.P. Gurson, I. Ozbay, B. Ozbay, G. Akyol, N.H. Akyol, Water Air Soil Pollut. 230, 220 (2019)

18. PPDB - Pesticide Properties Database, http://sitem.herts.ac.uk/aeru/iupac/index.htm

19. IUSS Working Group WRB. 2015. World Soil Resources Reports No. 106, http://www.fao.org/3/i3794en/I3794en.pdf

20. V.N. Kolupaeva, A.A. Kokoreva, A.A. Belik, P.A. Pletenev, Open Agr. 4(1), 599 (2019)

21. J. Kjaer, P. Olsen, T. Henriksen, and M. Ullum, Environ. Sci. Technol. 39(21), 8374 (2005)

22. J. Jebellie, S.O. Prasher, Am. Soc. Agr. Eng. 41(4), 1051 (1998)

23. T.B. Moorman, D.B. Jaynes, C.A. Cambardella, J.L. Hatfield, R.P. Pfeiffer, A.J. Morrow, J. Environ. Qual. 28, 35 (1999) 